\section{Regional Cinderellas}

SIR - Recent articles (Nature 368, 379 \& 383 ; 1994) emphasized how regions like Wales and some member states of the European Union (EU) might feel neglected when it came to allocation of funds by central authorities. In this respect, a confrontation with scientific output as measured by publication of mainstream research (data for 1981-92 from the Institute for Scientific Information) is enlightening.

The public financial input into Wales (3.7 per cent of total research council expenditure) correlates well with its scien-
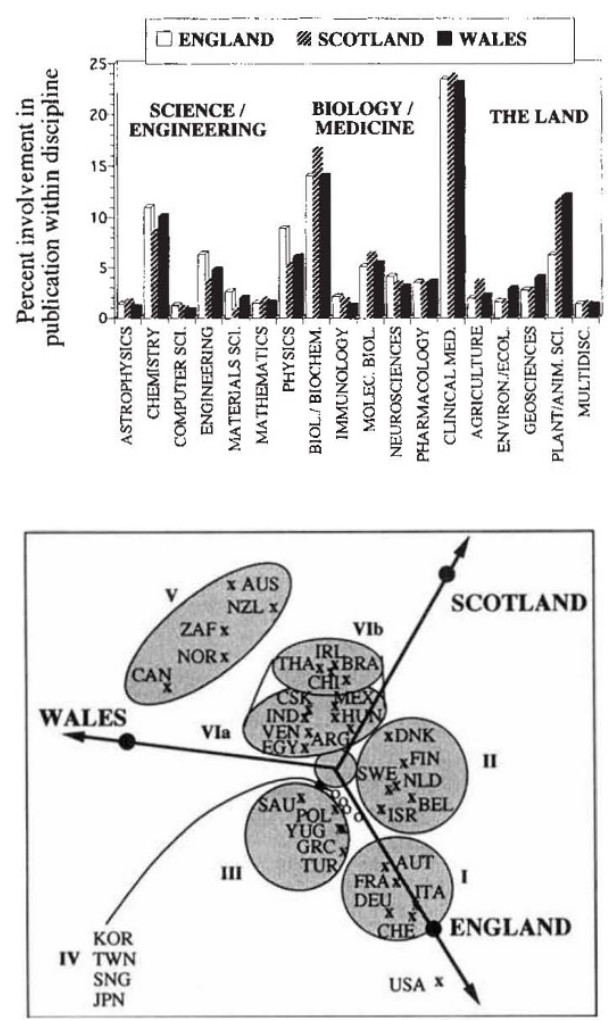

tific output (about 3.8 per cent of UK publications). Its publication pattern (top panel of figure) shows that, like Scotland, it focuses on disciplines connected with the land. In Wales, publication on ecological and environmental issues is comparatively high and probably linked to high National Environmental Research Council spending. Scotland receives more funds from the Medical Research Council and publishes preferentially in the life sciences as is expected of centres of medical excellence.

The publication pattern of a nation is tantamount to a signature. It reflects a nation's interest in a discipline and its capacity to perform mainstream research

Letters submitted for Correspondence should be typed, double-spaced, on one side of the paper only. in human, material, and financial terms. The publication patterns of 45 nations have been compared with those of the UK triad ( $>6$ million references) by Correspondence Factor Analysis ${ }^{1}$ (bottom panel of figure). Countries with similar signatures are close; countries analogous to a UK region are furthest along the vector linking the origin to this region.

England is a more powerful vector than Scotland or Wales and strongly associated with the United States. Do these two countries advance on every scientific front and hold the reins of upper-echelon journals in all disciplines? The countries closest to England that have opted for a similar balance of priorities are mostly EU members (I). On the Scottish side of the 'England' vector lie Israel, the Benelux, and Scandinavia (excluding Norway) (II). Scandinavia shares an interest with Scotland in life sciences. On the Welsh side are part of the Mediterranean rim, Poland and Saudi Arabia (III). Four Asian countries (Japan, Singapore, Taiwan, South Korea) (IV) are well lined along the vector leading to England and the United States.

Facing England, somewhat afield and nestled between Wales and Scotland, is a zone of several Commonwealth countries (V). The UK regions and the Commonwealth may be linked not only by British tradition but by a common heed for the land as Norway, highly mindful of its natural resources, belongs to the group. Also facing England, but more central, are India, Egypt, the former East European bloc, as well as Mexico, Argentina, and Venezuela (VIa). An adjacent small group (VIb), nearer to Scotland, includes Ireland, Brazil and Chile.

Taken together, these results suggest to us that culture, as forged both by geographic proximity and historical influence, strongly influences the pattern of scientific output by nations largely regardless of scientific merit. A preliminary timeanalysis seems to indicate a trend toward conformism in Western countries, which, if corroborated, might justify giving some 'regional cinderellas' more autonomy in selecting their own research policies.

\section{Tilu Ojasoo}

69 Alexandra $R d$,

Kew, Surrey TW9 2BT, UK

Jean-Christophe Doré

URA 401 CNRS,

Muséum National d'Histoire Naturelle, 75231 Paris Cedex 05, France

Jean-Françols Miquel

Laboratoire Stratégie et Technologie,

Ecole Centrale Paris,

92295 Châtenay-Malabry, France

1. Okubo, Y., Miquel, J. F., Frigoletto, L. \& Doré, J. C. Scientometrics 25, 321-351 (1992); 29, 271-297
(1994).

\section{Mars mission}

SIR - Tony Reichardt is correct in reporting (Nature 369, 3; 1994) that the Russianled mission Mars 94 "has fallen victim to financial, technical and scheduling problems" and that the launch has been delayed until 1996. The problems are well known and are due to the difficult financial and political circumstances of our Russian colleagues. The delay in the launch date of Mars 94 has been widely anticipated for many months. Nevertheless, it is a great tribute to the initiative and tenacity of the Russian Mars 94 scientists and engineers that the mission is still viable.

We would like to make one correction. You report that there were technical delays with the "German-built Argus platform for pointing the spacecraft's cameras". In fact Germany has never had any involvement in the construction of the platform, which, like the spacecraft itself, is a Russian responsibility. However, since the platform is critical also for a successful mission in 1996, discussions are taking place between the Russian, German and French sides to identify areas in which assistance could be provided to our Russian partners. Completion of the platform on schedule is crucial to the effective operation of the German and French instruments to be mounted upon it.

\section{Gerhard Neukum}

German Aerospace Research

Establishment (DLR),

Institute forPlanetary Exploration,

Berlin, Germany

\section{Vatican error}

SIR - Writing about the Pontifical Academy for Life (Nature 369, 352; 1994), Gerard LeBlond justifiably found fault with the sentence "life begins at the moment of conception". Of course the sentence assumes that life exists in the germ line before, during and after the moment of conception and that life goes on throughout the development of an organism; the statement, as LeBlond probably comprehends, was made to underline the beginning of a new individual, different from its parents, and this can occur only at the moment of conception when the genetic material of two germ cells contributes to create a different organism.

This point of view supports the development of a wide defence of unborn rights and justifies the great effort to create an Academy for Life which guarantees human rights from this mysterious moment onwards.

\section{J.A. Botella}

Departamento de Genética y Microbiología, Facultad de Biología,

Universidad de Murcia, Apdo. 4021, 30071 Spain 